\title{
Ampacity Test of 28 AWG Ribbon Cables
}

\author{
Erika Drennan \\ Fermi National Accelerator Laboratory \\ P.O. Box 500 \\ Batavia, Illinois 60510
}

April 1990 
TM \#1657

2100.000

Erika Drennan, EED

April 1990

$\mathrm{X} 4693$

MS \#220

Ampacity tests of $28 \mathrm{AWG}$ ribbon cables 


\section{Contents}

1 Summary 2

2 Testing procedures and results 2

2.1 Procedure and accuracy $\ldots \ldots \ldots \ldots \ldots \ldots$

2.2 Flat cable test results . . . . . . . . . . . . . . 3

2.3 Twist and flat cable test results . . . . . . . . 6 6

3 Conclusion 7

4 Recommendation for current limits 8

5 Acknowledgements 8 


\section{Summary}

This report contains the results of testing ribbon cables in order to determine the amount of current they can carry. In some experiments ribbon cables are used to power circuit boards and carry several amperes of current. These tests were required to establish safe operating current limits for electrical safety reviews. The basic principle behind these tests was to increase the amount of current passed through the ribbon cables until the insulation melted and the cable clearly became a fire hazard. As the current through the cable was increased the copper temperature was determined from the increased conductor resistance.

The tests were done on two different types of ribbon cables. One was the flat 26 conductor $28 A W G$ and the other was the twist and flat 26 conductor 28AWG ribbon cable, both of which are commonly used in the experiments. The flat cable was tested for current carrying capacity through three conductors and through a single conductor. The twist and flat cable was tested for current carrying capacity through a single conductor. It was found that the maximum single conductor ampacity for both cables is approximately $3 \mathrm{~A}$ and the three conductor ampacity for the flat cable is about $10 \mathrm{~A}$.

\section{Testing procedures and results}

\subsection{Procedure and accuracy}

Although for each of the following tests the cable was tested in a different manner, the basic procedure was the same. In all tests a DC current source was used to supply a constant current through the cable. The voltage across the cable was measured. From the voltage and current the resistance of the cable was calculated $\left(R_{\text {hot }}\right)$, and the change in the copper temperature $(\Delta T)$ was determined according to the formula:

$$
R_{\text {hot }}=R_{\text {cold }}+\alpha_{\text {cu }} \Delta T R_{\text {cold }}
$$

In the above formula $\alpha_{e u}$ is the resistance temperature coefficient of copper 0.004 and $R_{\text {codd }}$ is the resistance of the cable at room temperature. This cold resistance was calculated by passing a very low current $\sim 100 \mathrm{~mA}$ through the conductor and measuring the voltage drop across it. 


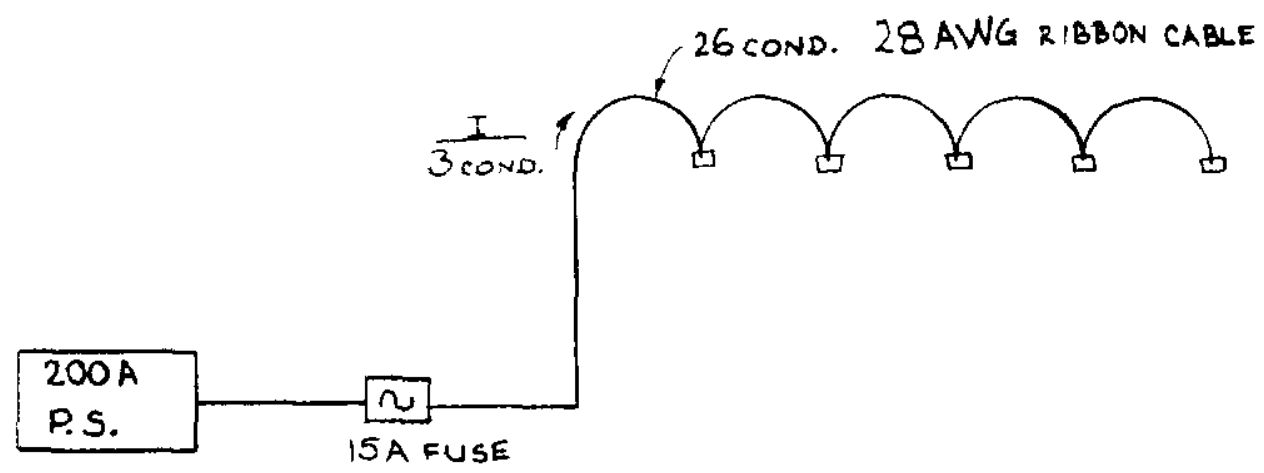

Figure 1: Experimental setup.

It is important to note that the $\Delta T$ calculated in this manner was very sensitive to changes in the current output of the power supply. In fact a $1 \%$ change in the current could easily cause a $5 \%$ change in $\Delta T$. Since the current wasn't this accurately monitored, we can say that the error in final copper temperature due to fluctuations in current is about $5 \%$. Some of the tests were repeated several times to make sure that the results are accurate. Taking into account all other sources of error, such as the change of a few degrees in the room temperature and changes in the airflow around the cable, it is safe to assume that the final copper temperatures are accurate within $\pm 5^{\circ} \mathrm{C}$.

\subsection{Flat cable test results}

The initial need for these tests was prompted by a setup in which three conductors of the flat cable were used to power several circuit boards. Since in most applications these cables carry current in the miliAmpere range, not much information was available on the performance of these cables when they carry higher currents. In the experimental setup the three conductors were fused for 15A. This setup is shown in Figure 1. The first test on this ribbon cable was done to see if passing $15 \mathrm{~A}$ through the three conductors, the cable could become a fire hazard. In the test a 12 inch piece of the ribbon cable was folded in a section to account for extra heat build up in places where the cable is not sufficiently air cooled like near the connecters. 15A was passed through the three conductors. This setup is shown in Figure 2. The temperature of the cable was measured using a thermometer, but later it was found that these measurements were not very accurate. Therefore the 


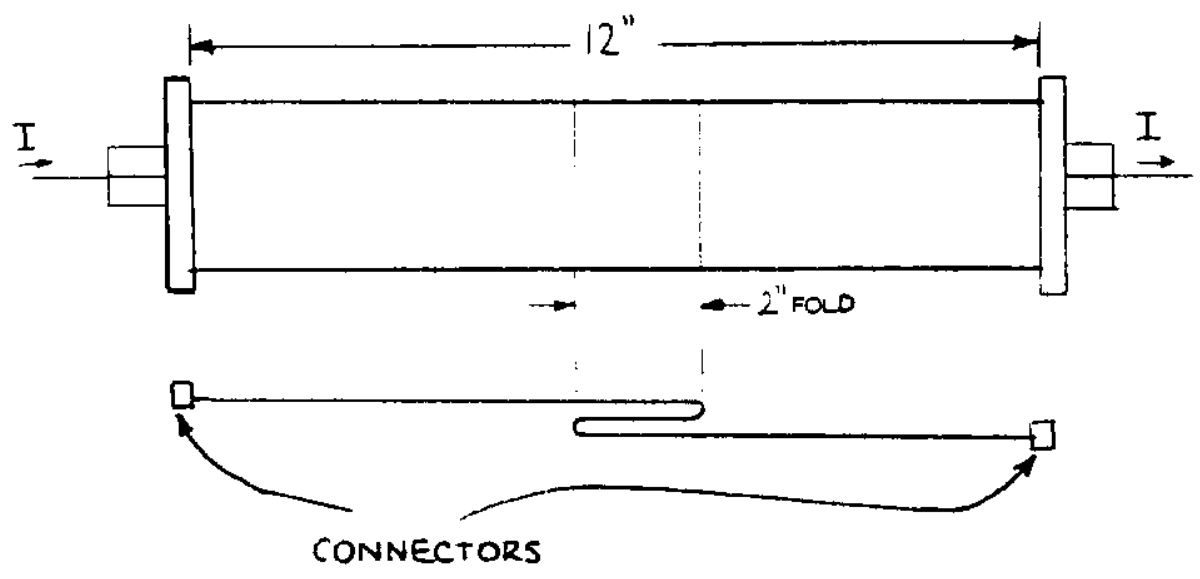

Figure 2: Flat ribbon cable setup for the three conductor test.

only results of this test are what could be observed watching the cable. It was found that the insulation on the cable softened everywhere and melted through where the cable was folded.

To further increase our understanding of the current capacity of this ribbon cable, several tests were done in which the setup was the same as is shown in Figure 2, but the fold was eliminated. Tests of the cable with current passing through it for several hours were done to see if there is a heat build-up that shorter tests would not take into account. No such effects were found, so later some of the test were done only until thermal equilibrium was reached. The current through the three conductors was increased by $5 \mathrm{~A}$ increments to $20 \mathrm{~A}$. At $20 \mathrm{~A}$ the insulation softened after just one minute, it was bubbling after four minutes carbonizing and smoking after five minutes. It important to note that even after the insulation was heavily smoking the conductor was still conducting current.

In this test the current was passed through the conductors through the same type of connectors that the circuit boards would plug into. Even when the ribbon cable was destroyed no damage was done to these connectors. The results of these tests are summarized in Table 1. 
Table 1: Results of the three conductor test for the flat 28AWG 26 conductor cable.

\begin{tabular}{|c|c|c|c|}
\hline Current & Testing time & $\begin{array}{c}\text { Final Cu } \\
\text { temperature }\end{array}$ & Notes \\
\hline $5 \mathrm{~A}$ & $3 \mathrm{hrs}$ & $29^{\circ} \mathrm{C}$ & No problems \\
\hline $8 \mathrm{~A}$ & $3 \mathrm{hrs}$ & $44^{\circ} \mathrm{C}$ & No problems \\
\hline $10 \mathrm{~A}$ & $3 \mathrm{hrs}$ & $55^{\circ} \mathrm{C}$ & Cable warm \\
\hline $15 \mathrm{~A}$ & $7 \mathrm{~min}$ & $112^{\circ} \mathrm{C}^{\circ}$ & $\begin{array}{c}\text { Insulation soft, } \\
\text { melts in fold }\end{array}$ \\
\hline 20 & $6 \mathrm{~min}$ & $255^{\circ} \mathrm{C}$ & $\begin{array}{c}\text { Insulation carbonizing, } \\
\text { Lots of smoke }\end{array}$ \\
\hline
\end{tabular}

- Final Cu temperatures are calculated by adding $\Delta T$ to a $25^{\circ} \mathrm{C}$ ambient temperature. For an industrial ambient of $40^{\circ} \mathrm{C} 15^{\circ} \mathrm{C}$ has to be added to all final Cu temperatures.

Measurement taken with no fold in the cable.

In the final part of the testing of this cable all 26 conductors were connected in series and current was passed through them. This setup is shown in Figure 3. The ampacity of single conductors can be studied this way. Currents of $1 \mathrm{~A}, 2 \mathrm{~A}$ and $4 \mathrm{~A}$ were passed through the ribbon cable. At $4 \mathrm{~A}$ the ribbon cable was very hot and the insulation softened. These tests were done only for a few minutes until thermal equilibrium was reached and the resistance of the cable stopped changing. A summery of these test results is given in Table 2.

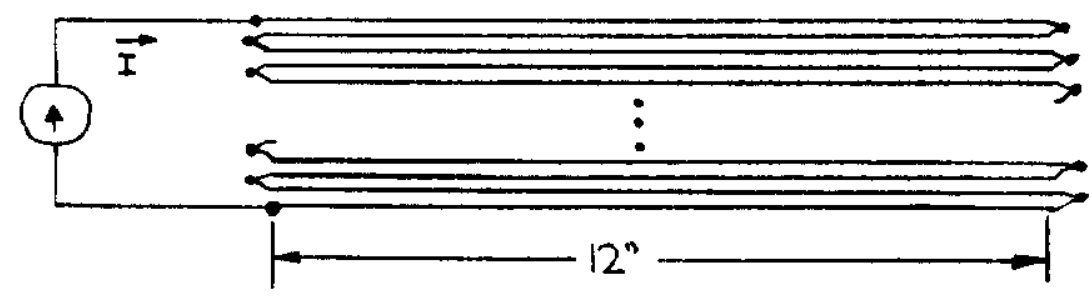

Figure 3: Flat single conductor test. 


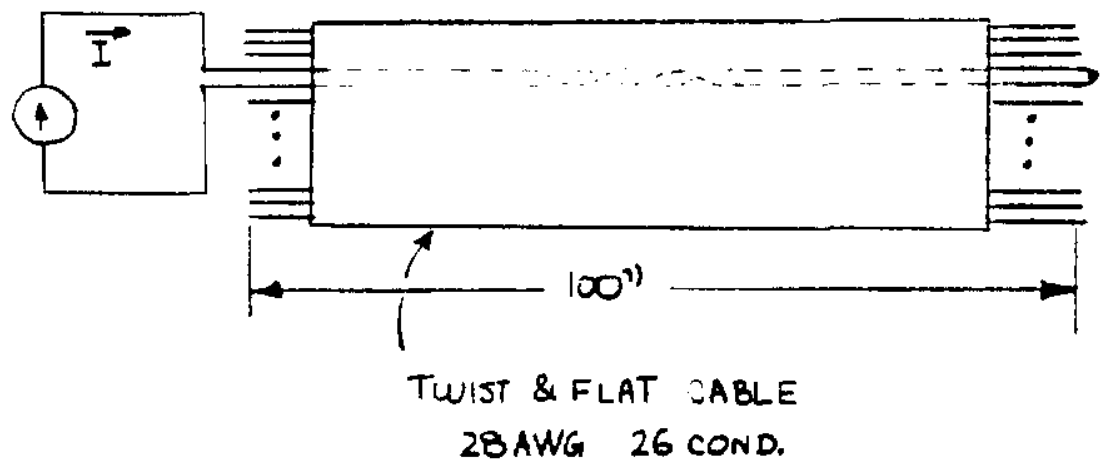

Figure 4: Cable connection for twist and flat test.

Table 2: Results of the single conductor test for the flat 26 cond. 28AWG cable.

\begin{tabular}{|c|c|c|c|}
\hline Current & Testing time & $\begin{array}{c}\text { Final Cu } \\
\text { temperature }\end{array}$ & Notes \\
\hline $1 \mathrm{~A}$ & $4 \mathrm{~min}$ & $26^{\circ} \mathrm{C}$ & No problems \\
\hline $2 \mathrm{~A}$ & $5 \mathrm{~min}$ & $41^{\circ} \mathrm{C}$ & No problems \\
\hline $4 \mathrm{~A}$ & $5 \mathrm{~min}$ & $106^{\circ} \mathrm{C}$ & $\begin{array}{c}\text { Cable very hot } \\
\text { and soft }\end{array}$ \\
\hline
\end{tabular}

in $25^{\circ} \mathrm{C}$ ambient

\subsection{Twist and flat cable test results}

Another ribbon cable commonly used in the experiments is the 26 conductor 28AWG twist and flat ribbon cable. Since this cable is also used to power circuit boards in some experiments its ampacity had to be determined. For this test two of the conductors of an $\sim 100$ inch cable were connected in series as shown in Figure 4. Current of $2 \mathrm{~A}$ and $3 \mathrm{~A}$ were passed through the conductors for 4 hours to see if there is a long term heat build-up. Since no such effect was found and the copper temperature of the cable remained constant after a specific current was applied for about 15 minutes, the tests at higher currents were done only until thermal equilibrium was reached. The results of the tests are given in Table 3. 
Table 3: Results of twist and flat 26 cond. 28AWG cable test.

\begin{tabular}{|c|c|c|c|}
\hline Current & Testing time & $\begin{array}{c}\text { Final } \mathrm{Cu} \\
\text { temperature }\end{array}$ & Notes \\
\hline $1 \mathrm{~A}$ & $5 \mathrm{~min}$ & $25^{\circ} \mathrm{C}$ & No problems \\
\hline $2 \mathrm{~A}$ & $4 \mathrm{hrs}$ & $40^{\circ} \mathrm{C}$ & No problems \\
\hline $3 \mathrm{~A}$ & $4 \mathrm{hrs}$ & $55^{\circ} \mathrm{C}$ & No problems \\
\hline $4 \mathrm{~A}$ & $30 \mathrm{~min}$ & $70^{\circ} \mathrm{C}$ & Conductor warm \\
\hline $5 \mathrm{~A}$ & $15 \mathrm{~min}$ & $97^{\circ} \mathrm{C}$ & Conductor hot \\
\hline $6 \mathrm{~A}$ & $15 \mathrm{~min}$ & $134^{\circ} \mathrm{C}$ & Conductor very hot \\
\hline $7 \mathrm{~A}$ & $15 \mathrm{~min}$ & $184^{\circ} \mathrm{C}$ & Insulation melting \\
\hline
\end{tabular}

in $25^{\circ} \mathrm{C}$ ambient

\section{Conclusion}

Data has been presented to determine the ampacities of the 26 conductor $28 \mathrm{AWG}$ flat and 26 conductor $28 \mathrm{AWG}$ twist and flat ribbon cables. Looking at the test results in Table 1 for the flat ribbon cable it seems that the three conductor ampacity is $10 \mathrm{~A}$ maximum. At $40^{\circ} \mathrm{C}$ ambient the final copper temperature would be about $70^{\circ} \mathrm{C}$ which is probably the temperature rating of the insulation. A $10 \mathrm{~A}$ rating through three conductors implies a single conductor rating of $\sim 3 \mathrm{~A}$. Although a $3 \mathrm{~A}$ single conductor test was not done with this cable, a $3 \mathrm{~A}$ single conductor ampacity seems reasonable from the final $\mathrm{Cu}$ temperatures at $2 \mathrm{~A}$ and $4 \mathrm{~A}$ (see Table 2). For the 26 conductor $28 \mathrm{AWG}$ twist and flat cable the final $\mathrm{Cu}$ temperature at $3 \mathrm{~A}$ was $55^{\circ} \mathrm{C}$ which at $40^{\circ} \mathrm{C}$ ambient would be $70^{\circ} \mathrm{C}$. Therefore it can be said that the single conductor ampacity of the twist and flat cable is about $3 \mathrm{~A}$.

A guideline for the current carrying capacity of single copper conductors copied from an Alpha catalog is attached. According to this sheet the ampacity of single 28AWG copper conductors in free air is $3 \mathrm{~A}$. Both the flat and twist and flat cables in these tests were 28AWG and the experimentally determined ampacities were found to be $\sim 3 \mathrm{~A}$. This result agrees well with the ampacities provided in the Alpha catalog, although the final copper temperatures of the above tests were somewhat lower then the ones given in the catalog. The reason for the discrepancy could be that the table is for single 
conductors, while the above tests were done for ribbon cables. It is possible that the extra conductors in the cable acted as a heat sink. It is important to realize that the results in this write-up hold exactly only for the ribbon cables specified.

\section{Recommendation for current limits}

The length of all 28AWG ribbon cables used for power distribution in excess of $1 \mathrm{~A}$ shall be less then $15 \mathrm{ft}$ long.

The current flowing through $28 \mathrm{AWG}$ ribbon cables shall be limited to $3 \mathrm{~A}$ maximum for one conductor per ribbon cable.

In applications where several adjacent conductors in one ribbon cable are used in parallel to carry currents in excess of $3 \mathrm{~A}$ total, a limit of $2.5 \mathrm{~A}$ for each conductor is recommended with the restriction that each parallel wire is solidly bonded together at the power supply and load connection, so that it is impossible for one of the parallel wires not to carry its share of the load current. Misalignment of plugged in printed circuit cards could lead to excessive conductor current and should therefore be impossible.

\section{NOTE:}

- The above recommendations have not yet been submitted to the Fermilab Electrical Safety Committee for approval. They are therefore subject to possible revision.

- Operation of ribbon cables within the recommended limits will be approved by the "Safety Review of Electronics Power Distribution Systems for Experiments" until the Electrical Safety Committee possibly mandates stricter future limits.

\section{Acknowledgements}

My thanks go to Age T. Visser for reviewing this report and for all the helpful suggestions he made concerning the tests as well as concerning some of the contents of the this write-up. 
Current carrying capacity is defined as the amperage a conductor can carry before melting either the conductor or the insulation. Heat. caused by an electrical current flowing through a conductor, will determine the amount of current a wire will handle. Theoretically, the amount of current that can be passed through a single bare copper wire can be increased until the heat generated reaches the melting temperature of the copper.

There are many factors which will ilmit the amount of current that can be passed through a wire. These major determining factors are:

\section{Conductor Stze:}

The larger the circular mil area, the greater the current capacity.

\section{Insulation:}

The amount of heat generated should never exceed the maximum temperature rating of the insulation.

\section{Ambient Temperature:}

The higher the ambient temperature, the less heat required to reach the maximum temperature rating of the insulation.

\section{Conductor Number:}

Heat dissipation is lessened as the number of individually insulated conductors, bundled together, is increased.

\section{Installation Conductors:}

Restricting the heat dissipation by installing the conductors in conduit, duct, trays or raceways lessens the current carrying capacity. This restriction can be alleviated somewhat by using proper ventilation methods. forced air cooling, etc.

Taking into account all the variables involved, no simple chart of current ratings can be developed and used as the final word when designing a system where amperage ratings can become critical.

The chart shows the current required to raise the temperatures of single insulated conductor in free air $\left(30^{\circ} \mathrm{C}\right.$ ambient) to the limits of various insulation types. The following table gives a derating factor to be used when the conductors are bundled. These charts should only be used as a guide when attempting to establish current ratings on conductor and cable.

\section{DERATING FACTORS FOA BUWDLED COUDUCTORS}

\begin{tabular}{|c|c|}
\hline Condio" & Betor ( $\mathrm{X}$ (1) \\
\hline $2-5$ & 0.8 \\
\hline $6-15$ & 0.7 \\
\hline $16-30$ & 0.5 \\
\hline
\end{tabular}

\begin{tabular}{|c|c|c|c|c|c|}
\hline $\begin{array}{l}\text { busulation } \\
\text { Matertals }\end{array}$ & 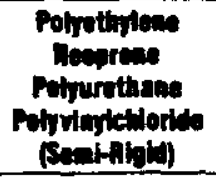 & 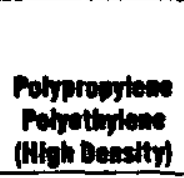 & 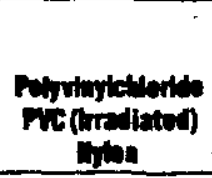 & 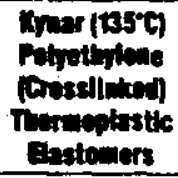 & Noten \\
\hline Copper Temp. & $80 \cdot \mathrm{C}$ & $90 \div \mathrm{C}$ & $105^{\circ} \mathrm{C}$ & $125^{\circ} \mathrm{C}$ & $200^{\circ} \mathrm{C}$ \\
\hline 30 AWG & 2 & 3 & 3 & 3 & 4 \\
\hline $24 A W G$ & 6 & 7 & 7 & 8 & 10 \\
\hline $22 \mathrm{AWG}$ & 8 & 9 & 10 & 11 & 13 \\
\hline 20 AWG & 10 & 12 & 13 & 14 & 17 \\
\hline 18 AWG & 15 & 17 & 18 & 20 & 24 \\
\hline 16 AWG & 19 & 22 & 24 & 26 & 32 \\
\hline 8AWG & 65 & 70 & 75 & 90 & 100 \\
\hline 6AWG & 95 & 100 & 105 & 125 & 135 \\
\hline 4 AWG & 125 & 135 & 145 & 170 & 180 \\
\hline 2AWG & 170 & 180 & 200 & 225 & 240 \\
\hline
\end{tabular}

